\title{
ANÁLISIS
}

\section{PERIODISMO CIUDADANO EN LAS EDICIONES DIGITALES, UNA APUESTA LIMITADA}

\section{Dolors Palau-Sampio}

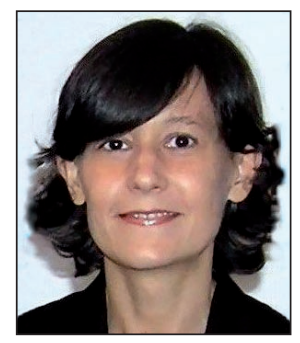

Dolors Palau-Sampio es licenciada y doctora en periodismo por la Universitat Autònoma de BarceIona (UAB). Ha trabajado como redactora del periódico Levante-EMV entre 1996-2005 y colaborado en distintas revistas. Desde 2000 es profesora de periodismo en la Universitat de València (UV). Ha publicado el libro Els estils periodístics. Maneres diverses de veure i construir la realitat (Servei de Publicacions de la Universitat de València, 2005).

Universitat de València Facultat de Filologia, Traducció i Comunicació Av. Blasco Ibáñez, 32. 46010 Valencia, España dolors.palau@uv.es

\section{Resumen}

En los últimos años, las ediciones electrónicas de los principales periódicos han abierto sus puertas al llamado periodismo ciudadano. Sin embargo, lejos de las declaraciones que presentan al lector como un periodista más, la realidad es muy diferente. Se comparan las secciones de participación informativa de cuatro ediciones digitales entre 2009 y la actualidad para analizar dos aspectos: si más allá de la invitación a "jugar a ser periodistas", los medios tienen una voluntad real de contar con los lectores y cuál es la respuesta de éstos.

\section{Palabras clave}

Participación, Medios digitales, Periodismo ciudadano, Ítems temáticos, Visibilidad.

Title: Citizen journalism in digital editions, a limited bet

\begin{abstract}
In recent years the digital media have opened their doors to so-called citizen journalism. Nevertheless, far from some declarations that present the reader as another journalist, the reality is very different. This article compares the sections of informative participation in four digital editions of printed newspapers from 2009 to nowadays in order to analyze two aspects: whether the media frankly trust the readers, beyond inviting them to play at being journalists; and what is the reader's response.
\end{abstract}

\section{Keywords}

Participation, Digital media, Citizen journalism, Thematic items, Visibility.

Palau-Sampio, Dolors. "Periodismo ciudadano en las ediciones digitales, una apuesta limitada". El profesional de la información, 2012, julio-agosto, v. 21, n. 4, pp. 369-374.

http://dx.doi.org/10.3145/epi.2012.jul.06

\section{Introducción}

Con la disponibilidad de la web 2.0 las ediciones digitales de algunos medios tradicionales abrieron sus páginas a los lectores, no como meros opinadores, comentaristas o participantes en foros - papeles que ya habían asumido- sino en el rol de protagonistas: como proveedores de información. Todo ello anunciado a bombo y platillo, con frases grandilocuentes que auguraban una especie de cambio revolucionario. Un lustro después de que cuatro periódicos españoles optaran por esta fórmula, los resultados están muy lejos de aquellos eufóricos inicios.

La etiqueta "periodismo ciudadano" remite a un fenómeno heterogéneo. Lo es su denominación -se habla, entre otros, de periodismo participativo, cívico, comunitario o 3.0- y, con ella, la variedad de manifestaciones a las que se asocia, desde iniciativas nacidas en la Red hasta otras que, como las que aquí se abordan, constituyen una apertura en los medios tradicionales. El periodismo ciudadano se vincula, 
según Varela, a la socialización de contenidos, que convierte el criterio de los ciudadanos en "guía y principal elemento de jerarquización" (2006, p. 99). Este periodismo 3.0 surge "desde los márgenes del sistema y desde la audiencia", para "devolver la inmediatez, el sentido de comunidad y la conexión con lo real a la información" (2006, p. 101).

\section{Alimentando el mito, entre la euforia teórica y la realidad}

Camino de las dos décadas de vida de los medios digitales, buena parte de los optimistas pronósticos sobre el alcance de la contribución ciudadana al caudal informativo está más cerca del mito que de la realidad, especialmente aquellos que inciden en sus virtudes democratizadoras. Como apuntan Almirón y Jarque, "la ecuación-mito que postula la tecnología como el bálsamo para sanar los males de la democracia es la que inspira a muchos de los defensores del periodismo digital, que la presentan como un quehacer profesional que indefectiblemente ahondará en una información más profunda, ética y plural gracias a la tecnología" (2008, p. 119). Uno de los ingredientes, indican, es la asociación de la tecnología con una mayor libertad en la difusión de opinión, en la creación y acceso a la información o en la participación en los contenidos de los medios (2008, p. 117). Ésta es la premisa que defienden investigadores como Pavlik para situar el periodismo ciudadano como "una parte crucial de la república electrónica del siglo XXI" (2005, p. 211).

Este periodismo auspiciado por la apertura de posibilidades de publicación en la Red cuestiona, en opinión de Bowman y Willis, el poder de los medios convencionales, al dejar en manos de los usuarios la selección y creación de contenidos. Su papel de gatekeepers, subrayan, está seriamente en peligro por la actuación de ciudadanos que asumen un rol activo en el proceso de recopilar, reportar, analizar y difundir noticias, con el objetivo de proporcionar la información independiente, fiable, precisa diversa, relevante que una democracia exige (2003, pp. 7-9).

\section{Algunas ediciones digitales abrieron sus} páginas a los lectores como proveedores de información, como un periodista más

La interactividad, uno de los elementos definitorios del entorno digital, tuvo su traducción participativa desde los primeros tiempos de la Red. Mediante encuestas, foros, chats, y más tarde comentarios a las noticias, los medios fueron abriendo espacios a la opinión. El terreno de la información seguía, en cambio, cultivado exclusivamente por los promotores de los medios, como una especie de demarcación sagrada.

Sin embargo, alentada por algunas iniciativas en el ámbito internacional y en plena efervescencia bloguera, la opción informativa empezó a llegar también a las ediciones digitales, fruto del proceso de "canibalización" (Orihuela, 2006, p. 158) ejercido por los medios convencionales a la hora de incorporar apuestas exitosas de la Red, pese al rechazo o la indiferencia inicial.

Gillmor, uno de los principales teóricos del periodismo 3.0 y el primero en incorporar blogs a un medio nacido fuera de la Red (San Jose mercury news, 1999), sostiene que no se puede hacer periodismo sin la colaboración de los lectores, sin entenderlo como una conversación con ellos. En su opinión, este periodismo ciudadano constituye una de las mayores amenazas para los medios tradicionales (2003, p. XIII). La eclosión del llamado We media no puede explicarse únicamente por las condiciones tecnológicas. Su irrupción coincide con una crisis de credibilidad de los medios tradicionales, que ha propiciado que muchos hayan optado por abrirse a la colaboración, para promover la transparencia, ampliar la agenda informativa o inocular el sentimiento de comunidad (Varela, 2006, pp. 138-143).

Cabe preguntarse, no obstante, ¿hasta qué punto es posible esta sustitución, el cambio de roles? ¿es periodista o hace periodismo cualquiera que publica en la Red o envía sus textos a una sección de participación ciudadana? Real, Agudiez y Príncipe se apresuran a dar una respuesta negativa, e inciden en dos pilares básicos del periodismo: el evidente interés -no curiosidad- general o público de los temas seleccionados y la necesidad de que estén "debidamente explicados e interpretados con veracidad, imparcialidad y honestidad profesional, y trasladados al público con rapidez sin que por ello se vea mermada su calidad" (2007, p. 193). La labor periodística, por tanto, trasciende la mera recolección de hechos -a la que se limita la mayoría de textos ciudadanos-, para poder interpretar, explicar y contextualizar las informaciones.

Rebillard cuestiona en especial la idea de que la Red rompe la línea divisoria entre creadores y consumidores. Según explica, la aportación de contenidos está lejos de ser un fenómeno social masivo, para concentrarse en una minoría que ya tenía contacto con la información cuando llegó internet. Sólo cuando una mayoría esté "armada intelectual y técnicamente" será posible que las prácticas efímeras se conviertan en "usos sociales verdaderamente estables" (2007, pp. 21-22).

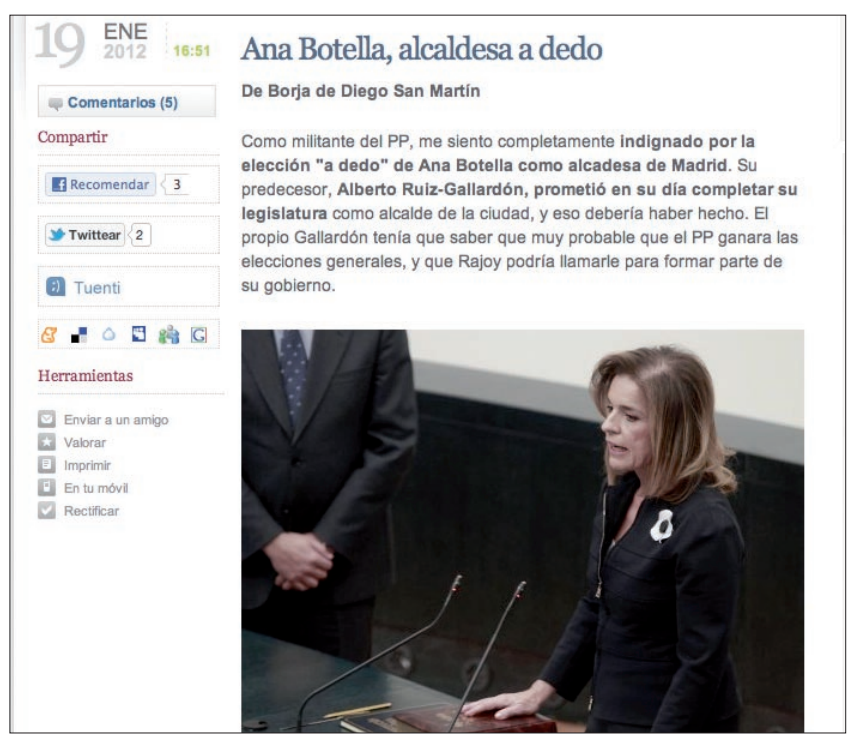

Imagen 1. Buena parte de las colaboraciones están más cerca de la opinión que de la información, como muestra este ejemplo de Elmundo.es 


\section{Internautas-periodistas y visibilidad de las noticias}

A finales de febrero de 2006 Elmundo.es lanzó una iniciativa novedosa: Ciudadano $M$, un blog de participación ciudadana en el que invitaba a los lectores a enviar "noticias, recomendaciones y críticas sobre Madrid y su comunidad". Unos meses después se sumaba Elperiodistadigital.com, con el objetivo de elaborar un periódico de once secciones a partir de la información que ofrecían sus blogueros. El país siguió estos pasos en abril de 2007, abriendo la sección Yo, periodista.

A los medios digitales no les dolieron prendas a la hora de exaltar el cambio de roles, de invitar al lector a situarse al otro lado de la barrera, un territorio hasta entonces vedado. El lema de Elpais.com constituía toda una declaración de intenciones: "Ahora los lectores de Elpais.com se convierten en periodistas". Tampoco Elmundo.es se quedaba atrás. "Conviértete en periodista", exhortaba desde Ciudadano $M$.

La calidad de los textos enviados por los lectores está lejos de los estándares de publicación del medio

La edición electrónica de Levante-EMV, en la línea de Elpais. com, motivaba al lector a renovar su papel tradicional: "Haz de reportero y cuéntanos, comparte todo aquello que te interesa". Aunque, en este caso, el estándar de noticiabilidad se alejaba del interés general: "Tus noticias. El festival de fin de curso de tu hijo, un reportaje sobre patrimonio en peligro en tu ciudad, tus vacaciones en Hawai o Gandía, el mejor día de tu vida". El aspecto noticiable se explicitaba mejor en el apartado de fotodenuncias: "Barrios abandonados por el ayuntamiento, suciedad, cruces peligrosos, puntos negros, vertederos incontrolados... Envíe una foto con unas líneas de texto denunciando aquello que merece ser mejorado y en lo que no se implican las administraciones".

Lasprovincias.es, por su parte, aludía a la participación a la hora de solicitar que los internautas enviasen noticias con fotografía, vídeo u otros documentos de interés: "Hemos habilitado esta nueva sección para seguir fomentando la interactividad". Añadía que serían incluidos en la sección -“e incluso publicados en el periódico de papel"-si, además de adaptarse al criterio periodístico del medio, estaban identificados y no contenían insultos.

Las declaraciones de los medios digitales a la hora de animar a sus lectores a colaborar sugerían una disposición privilegiada en las portadas, un espacio prioritario que invitase a la lectura. Sin embargo, la ubicación de estas contribuciones se ha caracterizado por su nula visibilidad en las páginas de acogida. Ninguna de las publicaciones ofrece las informaciones de los lectores en su portada. Es más, ni siquiera

\section{lasprovincias.eS}

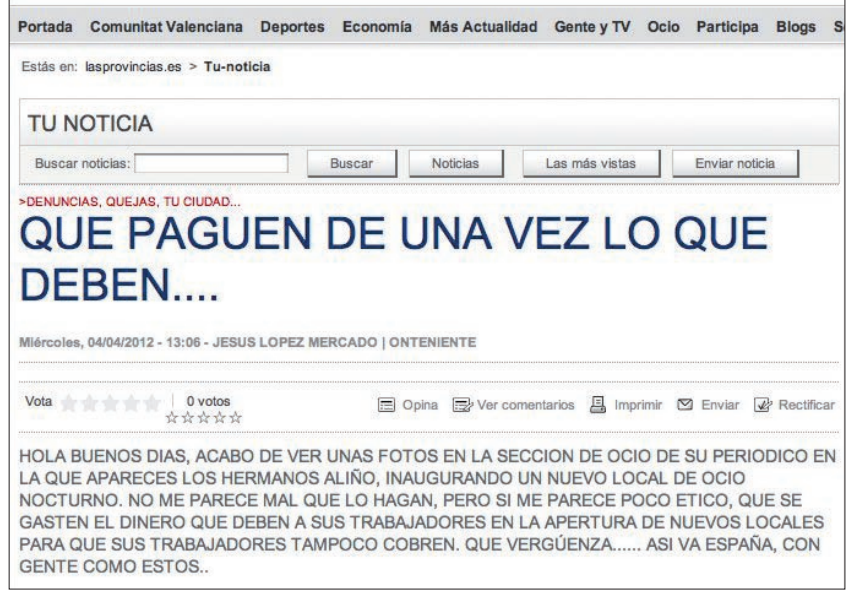

Imagen 2. Detalle de una de las noticias ciudadanas publicada en Lasprovincias.es

se sitúan en el espacio noticioso, sino que se emplazan en la sección de participación.

La ubicación de estas colaboraciones no es, ni mucho menos, una cuestión menor. Touboul señala que la gestión y el emplazamiento revela cómo se concibe la mediación periodística en la Web: los roles elegidos por los medios y los concedidos a los internautas (2006, p. 1). Pese a los cambios introducidos por internet, los medios no han renunciado a seguir ejerciendo su poder como productor principal de la información que será comentada o procesada (2006, p. 7). Así pues, la consideración "informativa” de las piezas que remiten los lectores queda por debajo de aquella que ofrecen los redactores o las agencias, los proveedores de noticias tradicionales.

Pese a declaraciones grandilocuentes y augurios revolucionarios, el control de los contenidos informativos sigue en las manos de siempre

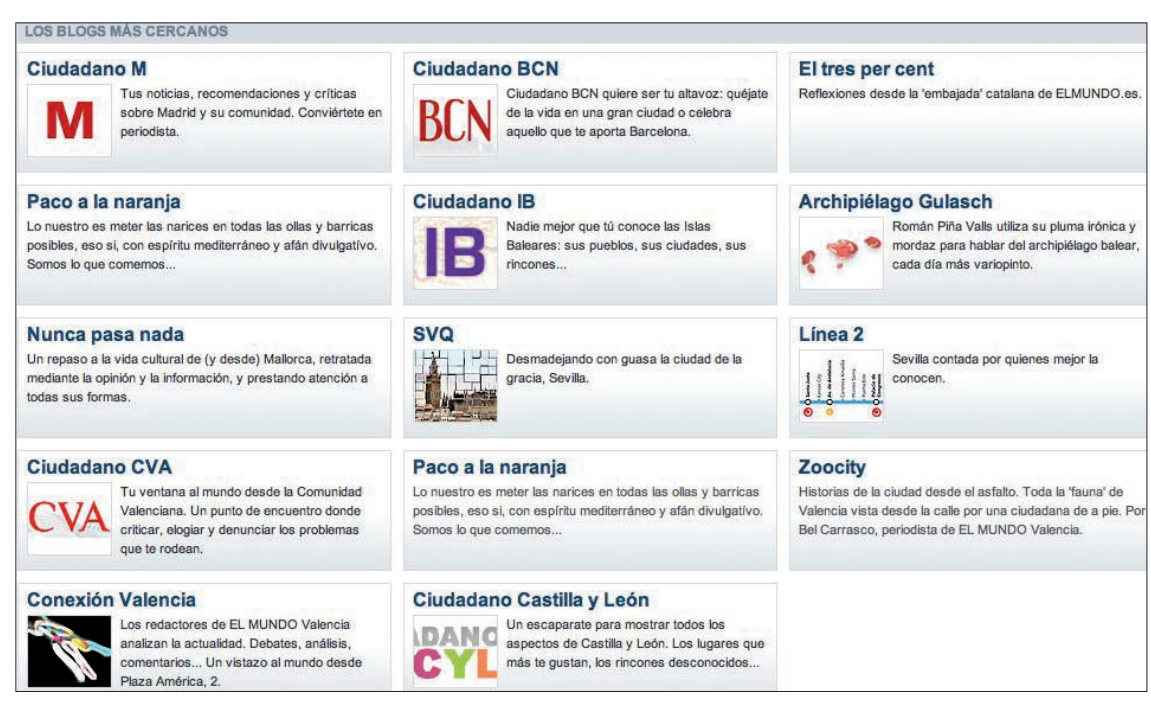

Imagen 3. Elmundo.es incluye la opción de periodismo ciudadano en la sección de blogs 


\section{foro}

\section{Posts de Fotodenuncias}

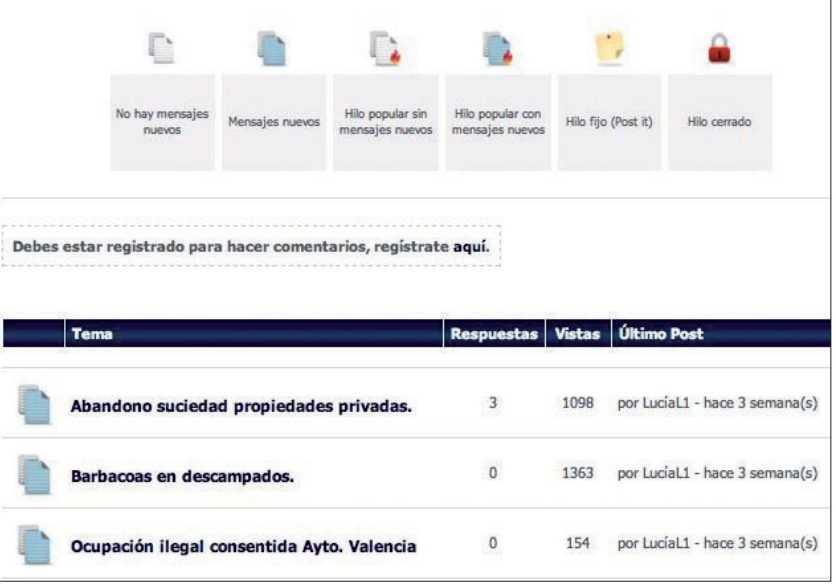

Imagen 4. Levante-emv.es sitúa la opción de fotodenuncias en el apartado de foros

\section{Mucho ruido para pocas nueces}

Con el objetivo de estudiar las características de la participación de los internautas en los espacios periodísticos, en 2009 se seleccionó una muestra de noticias aparecidas entre el 1 y el 25 de septiembre de ese año -un centenar-en cuatro publicaciones electrónicas: Elpais.com, Elmundo.es, Levante-emv.com y Lasprovincias.es. El análisis pretendía conocer la dinámica de participación, tanto desde el punto de vista de las opciones ofrecidas por el medio como de la respuesta de los lectores. Dos años y medio después, en marzo de 2012, se ha repetido la investigación, con los mismos medios, para conocer la evolución de una forma de participación que algunos auguraban revolucionaria. Las variables analizadas son de tipo cuantitativo y cualitativo, e incluyen: número de noticias publicadas, temas abordados (medio ambiente, infraestructuras, problemas vecinales, educación, sanidad, cultura, curiosidades y otros), inserción de fotografías (prueba visual o recurso-ilustración), tipo de aportación (denuncia, anuncio, opinión u otros), alcance (interés general o singular), contextualización (o no) y calidad en la presentación (textos en caja alta, desequilibrio en la extensión, errores de puntuación y/o ortografía).

\section{Si en 2009 Elpais.com sumaba más de 30 colaboraciones ciudadanas en 25 días, desde septiembre de 2010 no ha recibi- do entrada alguna}

\begin{tabular}{|l|c|c|c|c|}
\hline & $\begin{array}{c}\text { Elpais. } \\
\text { com }\end{array}$ & $\begin{array}{c}\text { Elmundo. } \\
\text { es }\end{array}$ & $\begin{array}{c}\text { Lasprovincias. } \\
\text { es }\end{array}$ & $\begin{array}{c}\text { Levante- } \\
\text { emv.es }\end{array}$ \\
\hline $1-25 / 09 / 2009$ & 32 & 40 & 27 & 3 \\
\hline $1-25 / 03 / 2012^{*}$ & - & 17 & 11 & - \\
\hline
\end{tabular}

*Elpais.com y Levante-emv.es no incluyen ninguna información aportada por los ciudadanos Cuadro 1. Aportaciones ciudadanas analizadas en las ediciones digitales

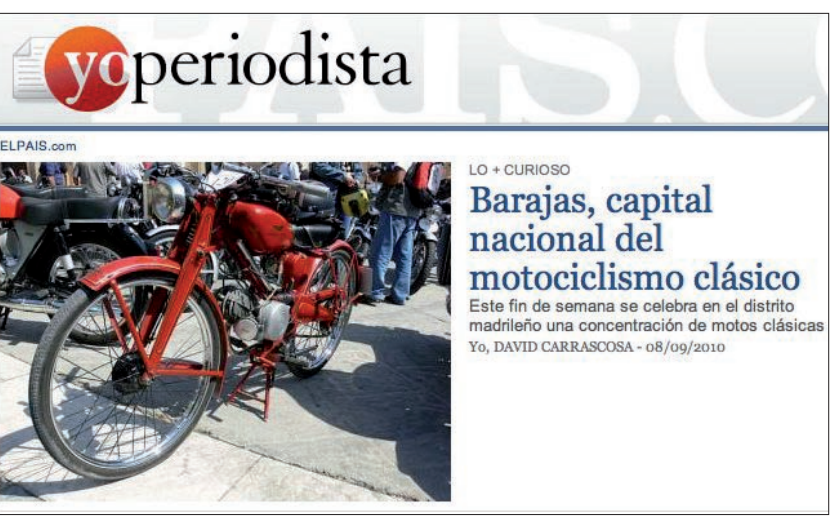

Imagen 5. Pese a estar activa, la ultima noticia de Yo, periodista es de septiembre de 2010

De las cuatro ediciones analizadas en 2009, Elpais.com presentaba el modelo más informativo -el resto estaba más cerca del comentario, anuncio, dietario o del simple desahogo. La propuesta de Yo, periodista, organizada en secciones, abría la colaboración a temas de medio ambiente, urbanismo, movilizaciones o actos cívicos y culturales. Pero, si en el estudio de 2009 sumaba más de una treintena de colaboraciones ciudadanas en 25 días, desde principios de septiembre de 2010 no ha recibido ninguna entrada.

Hasta entonces, tomando como referencia el archivo de Elpais.com, la selección de noticias comparte una serie de características:

- factualidad: presencia de temas (manifestaciones, protestas y fotodenuncias) en los que es posible exhibir una prueba documental-fotográfica-de lo relatado;

- proximidad: con informaciones de Medio ambiente o Problemas municipales a la cabeza -acompañadas de imagen-;

- las llamadas "noticias blandas", dedicadas a anunciar actos culturales y curiosidades.

En definitiva, temas que, de entrada, no suscitan controversia o requieren ser contrastados por el medio. Ello obliga a preguntarse por el nivel de confianza y fiabilidad respecto a las noticias que recibe, pero también por los temas que remiten los internautas y que finalmente son publicados.

En Lasprovincias.es, si en 2009 se contabilizaron una treintena de aportaciones en la sección Tus noticias, dos años y medio después esta opción se ha reducido a menos de la mitad. Los temas de este apartado -en el que mezclan noticias con la opinión, lo lúdico y las notas de prensa- se alejan de la línea informativa para involucrarse en el comentario personal, la promoción de eventos o en circunstancias más domésticas, como la búsqueda de una mascota. En general, la calidad de los contenidos textuales está lejos de los estándares de publicación del medio.

La edición electrónica de Elmundo.es es la que ha mantenido un modelo más dinámico hasta marzo de 2012, aunque con grandes diferencias. Así, mientras los blogs de Barcelona y Castilla y León están prácticamente inactivos, los de Madrid y Baleares han conservado un ritmo constante en 2010 y 2011 -una media de 200 noticias al año, en el primero, y de 110 , en el segundo- y el de la Comunidad Valenciana ha experimentado un importante retroceso -apenas una docena 


\begin{tabular}{l} 
YOPeriodista \\
\hline ELPAIS.com \\
Noticias sobre: Corrupción \\
Página 1 de 1 \\
FoToGRAFIA \\
La página web del PP provincial de Valencia, \\
pirateada por el 'caso Gürtel' \\
Un pirata informático ha alterado la página web del Partido Popular de la provincia de \\
Valencia... \\
Yo, JAVIER ARES \\
FOTOGRAFIA \\
Los municipales empiezan a pedir licencias en los \\
bares madrileños \\
Tras las detenciones de varios funcionarios del Ayuntamiento de Madrid por dar licencias \\
a cambio... \\
Yo, EDURNE POSADA \\
Página 1 de 1
\end{tabular}

Imagen 6. Elpais.com sólo incluye dos noticias en el apartado Corrupción, pero ninguna informa de un caso

de noticias en el último año. Con ello, las cerca de cuarenta colaboraciones contabilizadas en el análisis de 2009 se han reducido a la mitad, y esta tendencia se hace más evidente desde 2012. En la mayoría de los casos se trata de quejas y denuncias sobre urbanismo e infraestructuras y el formato blog influye de manera determinante en el carácter, no sólo de los contenidos sino también de la orientación, más en la línea de la opinión y la experiencia personal que de la propuesta informativa.

El cuarto medio analizado, Levante-emv.com, con una participación mínima en 2009 , ha suprimido el envío de textos y sólo mantiene la opción de remitir fotonoticias. Sin embargo, esta alternativa es también minoritaria, ya que en el último año apenas ha publicado una docena de denuncias ciudadanas, vinculadas a la suciedad y el estado de conservación de algunas zonas de Valencia.

\section{Conclusiones}

El contraste entre los vaticinios del alcance de la participación ciudadana y el balance actual obliga a poner entre paréntesis cierta euforia teórica, alimentada quizá por experiencias de colaboración en la Red (Wikipedia, Flickr...) y de creación colectiva. Pese a las grandilocuentes declaraciones, las ediciones digitales de los medios impresos analizados no pasan del mero formalismo en la apertura o disposición hacia el llamado periodismo ciudadano.

Si en 2009 una revisión de Elpais.com, Elmundo.es, Levante-emv.es y Lasprovincias.es mostraba cómo estas secciones quedaban relegadas a espacios secundarios, en 2012 están lejos de conquistar una presencia más sólida. No sólo no han conseguido hacerse visibles en la portada, sino que siguen relegadas a los apartados de participación, sin interferir el espacio informativo. La situación tampoco mejora desde el punto de vista de los lectores. Si en el anterior estudio la participación en estas secciones era escasa y con contenidos de carácter anecdótico, el paso del tiempo no ha contribuido a mejorar la situación. En uno de los digitales analizados se ha suprimido la opción de enviar textos (Levante-emv.es), en otro no se registran aportaciones desde hace año y medio (Elpais.com) y en los dos restantes la frecuencia de publicación de nuevas noticias se ha reducido de manera considerable (en torno a un 60\%). Por ello, más que una brecha en los canales tradicionales de comunicación, la aportación no profesional apenas constituye una grieta por la que se cuelan colaboraciones puntuales. Un análisis comparativo permitiría observar si esta tendencia se reproduce en los medios nativos, que han incorporado la participación como seña de identidad. También sería interesante ampliar el corpus de medios con publicaciones internacionales, para observar si la dinámica observada es general.

Un repaso a las contribuciones de los lectores permite concluir que la noticiabilidad de aquellas cuestiones que reportan se mueve más en el terreno del comentario personal o el anuncio que en el de la atención a temas de interés general, siquiera en el entorno más inmediato, de proximidad. La falta de contexto de las informaciones de los lectores priva a estas aportaciones del valor que tienen en los medios tradicionales, cuando el redactor no se limita a describir, sino que busca antecedentes, pregunta, cuestiona... En definitiva, profundiza en los hechos que, tal como se presentan en las ediciones electrónicas, no superan el tono epidérmico y, a menudo, visceral.

Este balance lleva a plantearse hasta qué punto los medios tradicionales están dispuestos a abrir su modelo a la colaboración ciudadana, a fomentarla e incentivarla, más allá de un cierto carácter lúdico - dejar al lector que se sienta periodista-, de marketing o de moda. En esta línea avanzan las reflexiones que invitan a matizar la euforia de algunos teóricos, a proyectar el foco de atención en las experiencias reales y a no dejarse cegar con las promesas tecno-revolucionarias, surgidas al calor y el éxito de iniciativas muy aisladas.

La colaboración ciudadana está más cerca del carácter lúdico, de marketing o de moda que de una voluntad real de incorporación por parte de los medios

\section{lasprovincias.es}

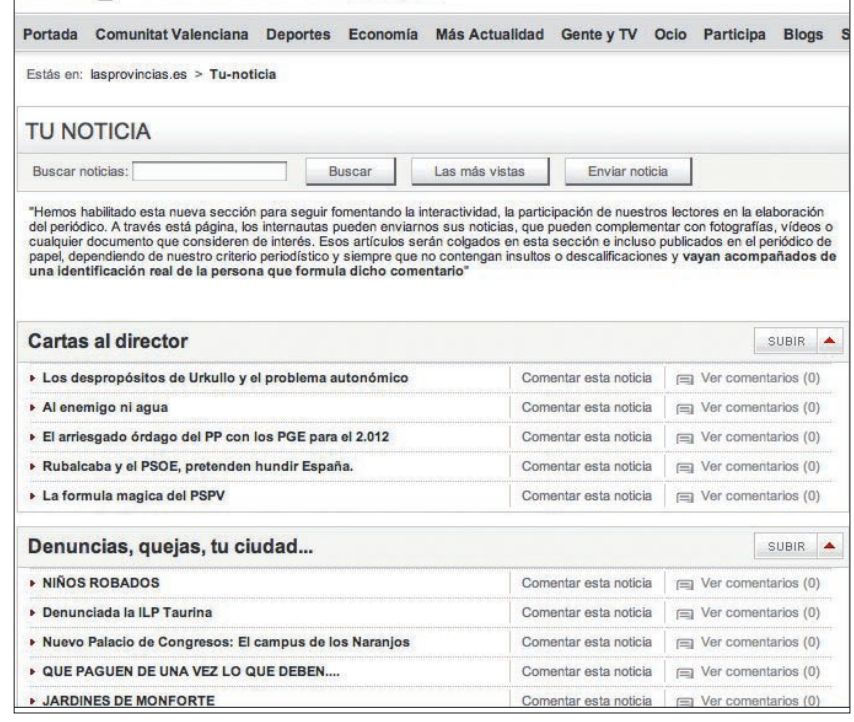

Imagen 7. Lasprovincias.es sitúa las noticias ciudadanas junto a la participación 


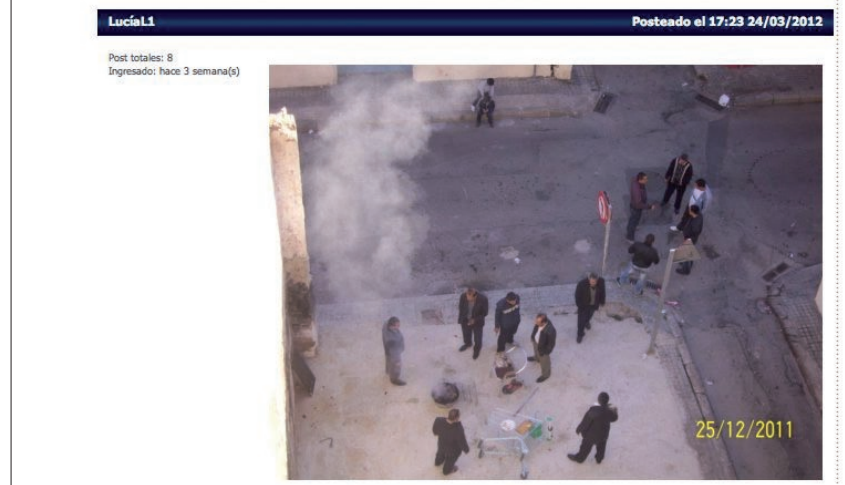

Esta es una estampa habitual en nuestro barrio, al avisar a la policia local nos dicen que ellos atienden por prioridades ... nunca vienen.

Se esta consintiendo la degradación de nuestro barrio el Cabanyal y alentándola.

Denunciar contenido inapropiado

Imagen 8. Levante-emv.es sólo permite enviar fotografías

\section{Bibliografía}

Almirón, Núria; Jarque, Josep M. El mito digital. Discursos hegemónicos sobre internet y periodismo. Barcelona: Anthropos, 2008. ISBN: 9878476588666

Bowman, Shayne; Willis, Chris. We media. How audiences are shaping the future of news and information, 2003.

http://www.hypergene.net/wemedia/download/we_me dia.pdf
Gillmor, Dan. We the media. Grassroots journalism by the people for the people. Stanford: O'Reilly, 2004.

http://oreilly.com/catalog/9780596007331/book/index.csp

Orihuela, José-Luis. La revolución de los blogs. Madrid: Esfera de los libros, 2006. ISBN: 8497344987

Pavlik, John V. El periodismo y los nuevos medios de comunicación. Barcelona: Paidós, 2005. ISBN: 9788449317309

Real, Elena; Agudiez, Pinar; Príncipe, Sergio. "Periodismo ciudadano versus periodismo profesional: ¿somos todos periodistas?". Estudios sobre el mensaje periodístico, 2007, n. 13 , pp. 189-212.

Rebillard, François. "Le journalisme participatif, de l'idéologie à la pratique". Argumentum, 2007, n. 6, pp. 11-23.

http://www.fssp.uaic.ro/argumentum/numarul\%206/01_ Rebillard.pdf

Touboul, Annelise. "Gestion de l'interactivité par la presse en ligne: exploitation et relégation de la parole profane". En: Colloque document numérique et société, Fribourg, 2006, pp. 1-7.

Varela, Juan. "Periodismo participativo: el periodismo 3.0". En: Rojas, Octavio I. et al. Blogs. La conversación en internet que está revolucionando los medios, empresas y ciudadanos. Madrid: ESIC, 2006, pp. 83-169. ISBN: 978847356274

\section{Documentación audiovisual}

\section{Mercedes Caridad, Tony Hernández, David Rodríguez y Belén Pérez}

El tratamiento digital de los contenidos, que se ha generalizado en todo el mundo, ha aumentado la complejidad de la documentación audiovisual. ¿Cuál será su influencia sobre el papel de los documentalistas audiovisuales en un futuro que ya se ha hecho presente? $Y$ ello sin

\section{Documentación audiovisual}

Mercedes Caridad, Tony Hernández David Rodríguez y Belén Pérez olvidar la visión comercial y legal de esas imágenes y sonidos: ¿quién las posee? ¿quién las controla?

Esta obra presenta una reflexión, en parte teórica y en parte aplicada que, sin olvidar los orígenes de la documentación audiovisual, responde a estos importantes interrogantes, con especial atención a la preservación, la gestión y la descripción de los contenidos. También incluye una relación de las fuentes documentales más relevantes del sector audiovisual, así como el estudio de las principales iniciativas políticas para el fomento de la industria de la imagen y el sonido tanto en Europa como en Estados Unidos.

Mercedes Caridad-Sebastián (catedrática), Tony Hernández-Pérez (profesor titular), David RodríguezMateos (profesor ayudante doctor) y Belén PérezLorenzo (profesora asociada) pertenecen al Departamento de Biblioteconomía y Documentación de la Universidad Carlos III de Madrid.

Caridad, Mercedes et al.

Documentación audiovisual, 2011, 232 pp.

Editorial Síntesis

ISBN: 9788497567466

ISBN Digital: 9788499586175

Precio (papel): $21 €$; eBook: 13,10€ 